\title{
Yeast Systems Biology: Model organism and Cell Factory
}

\author{
Nielsen, Jens
}

Published in:

Biotechnology Journal

Link to article, DOI:

10.1002/biot.201800421

Publication date:

2019

Document Version

Peer reviewed version

Link back to DTU Orbit

\section{Citation (APA):}

Nielsen, J. (2019). Yeast Systems Biology: Model organism and Cell Factory. Biotechnology Journal, 14(9), [e1800421]. https://doi.org/10.1002/biot.201800421

\section{General rights}

Copyright and moral rights for the publications made accessible in the public portal are retained by the authors and/or other copyright owners and it is a condition of accessing publications that users recognise and abide by the legal requirements associated with these rights.

- Users may download and print one copy of any publication from the public portal for the purpose of private study or research.

- You may not further distribute the material or use it for any profit-making activity or commercial gain

- You may freely distribute the URL identifying the publication in the public portal

If you believe that this document breaches copyright please contact us providing details, and we will remove access to the work immediately and investigate your claim. 


\section{Yeast Systems Biology: Model organism and Cell Factory}

Jens Nielsen ${ }^{1,2,3}$

${ }^{1}$ BioInnovation Institute, Ole Måløes Vej 3, DK2200 Copenhagen N, Denmark

${ }^{2}$ Department of Biology and Biological Engineering, Chalmers University of Technology, Kemivägen 10, SE412 96 Gothenburg, Sweden

${ }^{3}$ Novo Nordisk Foundation Center for Biosustainability, Technical University of Denmark, Building 220, DK2800 Kgs. Lyngby, Denmark

E-mail: nielsenj@chalmers.se

Keywords: cell factories, metabolic engineering, metabolic models, Saccharomyces cerevisiae, synthetic biology

For thousands of years the yeast Saccharomyces cerevisiae has served as a cell factory for the production of bread, beer, and wine. In more recent years, this yeast has also served as a cell factory for producing many different fuels, chemicals, food ingredients and pharmaceuticals. S. cerevisiae, however, has also served as a very important model organism for studying eukaryal biology, and even today many new discoveries, important for the treatment of human diseases, are made using this yeast as a model organism. Here I will provide a brief review of the use of $S$. cerevisiae as a model organism for studying eukaryal biology, its use as a cell factory, and how advances in systems biology underpins developments in both these areas.

This article has been accepted for publication and undergone full peer review but has not been through the copyediting, typesetting, pagination and proofreading process, which may lead to differences between this version and the Version of Record. Please cite this article as doi: 10.1002/biot.201800421.

This article is protected by copyright. All rights reserved. 
Graphical Abstract

\section{2-3 sentence summary:}

Through engineering yeast metabolism it is possible to produce many different molecules finding applications as biofuels, chemicals and pharmaceuticals. Relying on the extensive knowledge base of yeast, due to its many years of use as a model organism, assist in improving new design strategies, but also advancement in systems biology has enabled improved design of efficient cell factories.

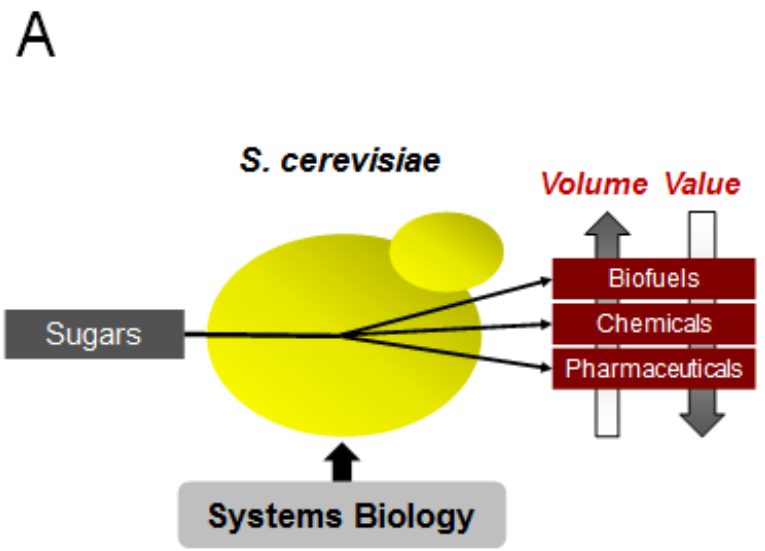

\section{Introduction}

The first beers were probably produced in China around 7.000 BCE and in Mesopotamia and Egypt around 3.500-3.100 BCE (1). However, there are strong indications that yeast was already used 10.000 BCE to raise bread (2). Through thousands years of development, yeast became domesticated for improved use in the production of bread, beer and wine. It was, however, first in the $19^{\text {th }}$ century that the French researcher Louis Pasteur demonstrated that the formation of alcohol in beer and wine production was not a spontaneous chemical conversion process, but required living cells. This enabled the Danish researcher Emil Christian Hansen, working at the Carlsberg Laboratory, to be the first to isolate yeast responsible for beer fermentation, allowing the Carlsberg brewery to significantly improve the quality of their beer production (3). Research carried out at the Carlsberg Laboratory played an important role in establishing fundamental research on yeast, as well as on many other aspects related to beer production. It subsequently played an instrumental role in establishing the role of yeast as a model organism for studying eukaryal cells.

The original yeast species isolated by Hansen was Saccharomyces carlsbergensis, also known as lager yeast, which was later renamed as $S$. pastorianus that was recently shown to be a hybrid between $S$. cerevisiae and $S$. eubayanus (2). The approach for isolation of yeast species, developed by Hansen, was rapidly implemented resulting in the isolation of S. cerevisiae, now known as Baker's yeast,

This article is protected by copyright. All rights reserved. 
which today is by far the most dominantly used yeast species in fundamental studies and as a cell factory. For this reason, even though other yeast species are applied as cell factories and as model organisms, the term "yeast" often implies referral to $S$. cerevisiae and throughout this review yeast will therefore refer mainly to this species. Despite many years of domestication of $S$. cerevisiae, sequencing of 1,011 strains has shown that there is relatively small genomic variability between wild strains and strains used for the production of bread and various fermented beverages (4), probably due to this yeast's natural habitat being associated with production of fermented beverages, e.g. on grapes. Furthermore, genome analysis points to a single "out-ofChina” origin for S. cerevisiae (4).

Here I will review the use of S. cerevisiae as a model organism and as a cell factory. I will further argue how systems biology has been pioneered using yeast, and how developments in systems biology of this organism has underpinned the continuous use of yeast as a model organism and an even wider use of it as a cell factory in the future.

\section{Yeast as a model organism}

The wide use of yeast as a model organism is clearly demonstrated by the fact alone that since 2001 three Nobel Prizes in Physiology or Medicine have been awarded based on classical forward genetics using this organism (5). Hartwell, Nurse and Hunt were awarded the prize in 2001 "for their discoveries of key regulators of the cell cycle”. Leland Hartwell worked with S. cerevisiae, whilst Paul Nurse worked with Schizosaccharomyces pombe (fission yeast), another widely used model yeast, and Tim Hunt used sea urchin eggs in his cell cycle studies. In 2013 the prize was awarded to Rothman, Scheckman and Südhof "for their ground-breaking work on cell membrane vesicle trafficking”, with Randy Scheckman using yeast in his studies for identifying many key components of the protein secretory pathway; a pathway that today is exploited for the production of recombinant proteins for pharmaceuticals, establishing a billion dollar industry (6). In 2016, Yoshinori Ohsumi received the Nobel Prize for "his discoveries of the mechanisms for autophagy", wherein practically all his ground-breaking work was accomplished using yeast as the model system, which he later confirmed to be conserved in higher eukaryal cells. Many other Nobel Prizes have also been given to researchers who used yeast as model system in their research work (5). Among these are Günther Blobel in 1999 (Physiology or Medicine) for the discovery that proteins have intrinsic signals which govern their transport and localization in the cell, Jack Szostak and Elizabeth Blackburn in 2009 (Physiology or Medicine) for their discovery of how chromosomes are protected by telomeres and the enzyme telomerase, Roger Kornberg in 2006 (Chemistry) for his studies of the molecular basis of eukaryotic transcription (much based on studying the GAL-regulon in yeast), Osamu Shimomura, Martin Chalfie and Roger Y. Tsien in 2008 (Chemistry) for the discovery and development of the green fluorescent protein where expression in yeast was instrumental for their work, Aaron Ciechanover, Avram Hershko and Irwin Rose in 2004 (Chemistry) for the discovery of ubiquitin-

This article is protected by copyright. All rights reserved. 
mediated protein degradation. In many of these cases classical biochemistry studies were combined with the power of classical yeast genetics (7), methods which remain in use today and which are increasingly being applied in a high-throughput fashion.

The success of using yeast as a model organism is due to the high degree of conservation of many key cellular processes between yeast and human cells, e.g. autophagy, protein translocation and secretion, endoplasmic reticulum associated protein degradation, heat shock, and protein folding and chaperone functions. At the gene level there is also a high degree of conservation, as $47 \%$ of 414 essential yeast genes with a 1:1 human ortholog can be replaced by their human orthologs (8). Finally, conservation of many key signal transduction processes between yeast and human is indicative of conserved protein-protein interactions, regulation hierarchies, and signal cross-talk. Prominent examples are Snf1 and Tor1/Tor2, which are two dominant regulators of metabolism, protein synthesis and cell proliferation (Fig. 1). The energy sensor Snf1, in humans called AMP activated kinase (AMPK), was first discovered in yeast for controlling the use of alternative carbon sources such as sucrose, maltose and galactose (Snf1 stands for sucrose non-fermenting) (9), a control which it exerts through repression of the transcription factor Mig1. Later Snf1 was also found to control the use of non-fermentative carbon sources such as ethanol and glycerol, through activation of the transcription factors Cat8 and Adr1 (Fig. 1). AMPK (Snf1) is highly conserved in the eukaryal Kingdom and its regulatory repertoire includes both activation of energy generation, i.e. glycolysis, alternative carbon source utilization, and $\beta$-oxidation, and repression of energy expenditure, i.e. amino acid biosynthesis, lipid biosynthesis, and protein translation. A number of studies as well as systems biology analysis of a snf1 mutant have shown these roles to also be conserved in yeast (10) (Fig. 1). Furthermore, as an energy sensor Snf1 is also able to activate multiple stress response pathways via the transcription factors Msn2 and Msn4 (Fig. 1).

Snf1 interacts closely with another protein kinase Tor (target of rapamycin), which has two paralogs in yeast, Tor1 and Tor2. Complexes centered around these kinases, TORC1 and TORC2, exert different functions in yeast, but combined, they have the same function as the TORC1 complex in human cells, despite only TORC1 in yeast being sensitive to rapamycin. The Tor-complexes sense nutrients, in particular, the level of nitrogen sources, and activates a number of processes required for cell proliferation such as stimulating protein biosynthesis, ribosome biogenesis, meiosis and cell cycling, while repressing processes such as autophagy, retrograde response, stress response and nitrogen catabolite repression (Fig. 1). In human cells, there is cross talk between Snf1 and Tor (Fig. 1), a feat that does not seem to be conserved in yeast (11), even though many of the same processes regulated by Tor are found to be the same in human and yeast cells (11).

Sir2 (SIRT1 in humans) is another important sensor for the cellular metabolic state first characterized in yeast. This enzyme deacetylates DNA and proteins using $\mathrm{NAD}^{+}$

This article is protected by copyright. All rights reserved. 
as a substrate, and hereby becomes a sensor of redox levels in the cell. In human cells SIRT1 has also been found to activate AMPK via its upstream protein kinases, but this connection has so far not been confirmed in yeast.

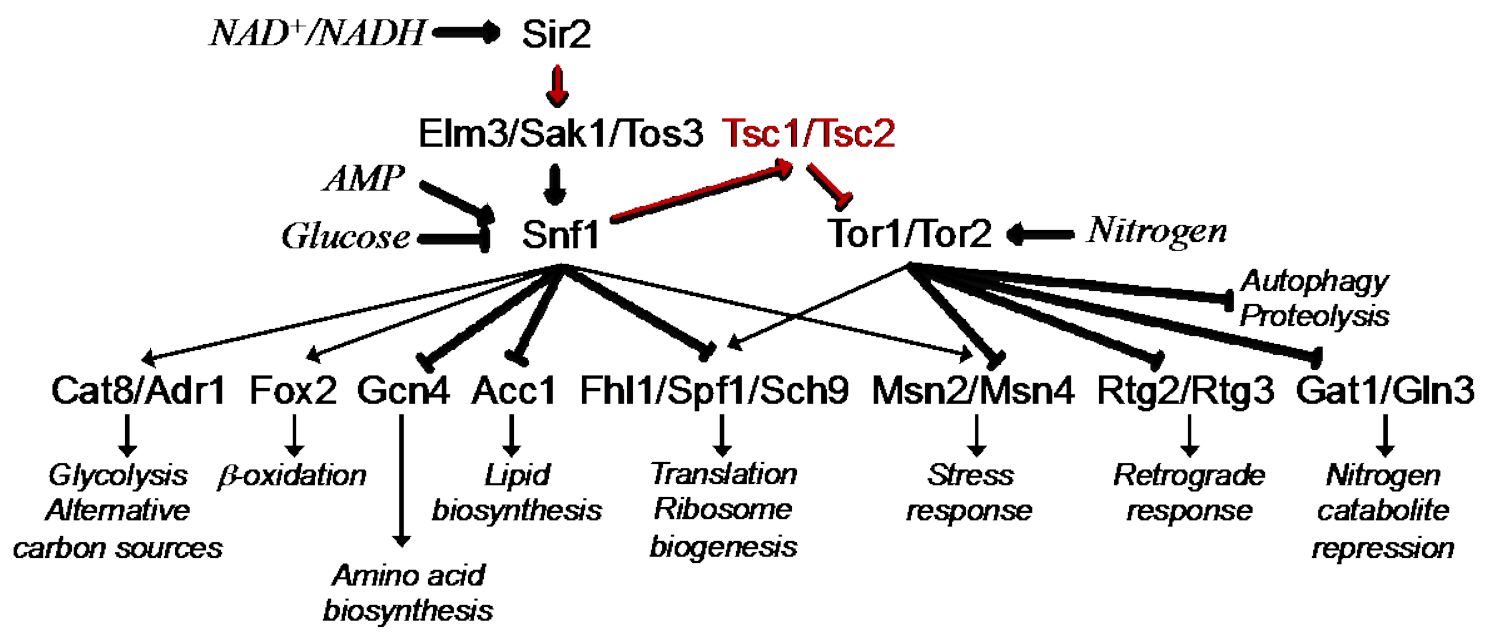

Fig. 1 The key role of Snf1 and Tor1/Tor2 in regulation of yeast metabolism. The lower level of proteins are all transcription factors that control expression of genes associated with the processes specified in italics. The connections marked in red have not been proven in yeast, but have been identified in human cells.

With the overlap of regulation, and the possible cross talk between Snf1, Tor1/Tor2 and Sir2, these key regulators clearly play a very important role in maintaining metabolic homeostasis in the cell. Conservation of these regulators and their major effectors from yeast to human have made yeast research indispensable for understanding the fundamental principles in cell biology, and also highly relevant to human health and disease. Finally, understanding these nutrient sensing, information integration, i.e. sensing energy levels (AMP/ATP ratio), nitrogen levels and the $\mathrm{NAD}^{+} / \mathrm{NADH}$ ratio, and gene expression control mechanisms have enabled rewiring of yeast metabolism to over-produce many metabolites, propagating the extensive use of yeast as a cell factory and laying the foundations to using yeast as a model organism to pioneer the field of systems biology.

\section{Yeast as a cell factory}

With its extensive use in the production of beer and wine, it was natural that $S$. cerevisiae became extended towards use in ethanol production. Ethanol, although commonly associated with alcoholic beverages, was also used as a transportation fuel in the early days of automobile development. Today, it is by far the most produced biofuel, in 2017, bioethanol production in the USA alone being more than 60 billion liters, whilst in Brazil it is about 30 billion liters, and in the rest of the World about 15 billion liters. Due to the wide use of yeast for bioethanol production, the fermentation industry has a large preference for this organism as a cell factory also for the production of many other fuels and chemicals. Furthermore, it is often the preferred

This article is protected by copyright. All rights reserved. 
cell factory for the production of food-grade-products due to its long use in the food industry. The choice of cell factory does, however, depend on many different factors (Table 1), and for diols such as 1,3 propanediol and 1,4 butanediol, both which are used as commodity chemicals, the Gram-negative bacteria Escherichia coli has historically been the preferred cell factory, due to its ability to attain very high production rates and the relatively low toxicity of these compounds $(12,13)$. In Table $1 \mathrm{I}$ benchmark four widely used cell factories in respect to several important traits a cell factory should have. Although it is obvious that there is no single cell factory that scores high on all desired traits, S. cerevisiae still often comes out as the preferred cell factory, in particular for its production of organic acids as well natural products that require expression of plant P450 enzymes.

For these reasons and its robustness for producing many different chemicals (Table 2), S. cerevisiae is often referred to as a so-called platform cell factory (Fig. 2A) (14). Many of these chemicals, however, have only been produced in small amounts in the laboratory, therefore implementation of an industrial process will usually require iterative optimization in strain and fermentation process, through which the titer, rate and yield (TRY) of the cell factory are all improved. Improvement of the TRY requires extensive engineering of central carbon metabolism, as not only the pathway leading to the product of interest has to be optimized, but also the provision of the precursor metabolite(s) and co-factors need to be optimized (15). This improvement is therefore costly and takes several years (Fig. 2B), e.g. on the order of USD50 millions and 5-8 years (15). In particular for commodity type products, such as biofuels and platform chemicals used e.g. for polymer production, there are strict requirements on the TRY, and generally one has to reach $>90 \%$ of the theoretical yield of product from the substrate to have an economically viable process. This often requires major rewiring of central carbon metabolism, such that this is tailored to supply precursor metabolite(s) and co-factors that are used in the production pathway. Thus, in order to improve the TRY of the sesquiterpene farnesene, for example, that can be used as a biofuel as well as in the synthesis of squalene and other valuable chemicals, researchers from the biotech company Amyris completely rewired central carbon metabolism in order to ensure a high TRY (16). This rewiring involved expression of a heterologous phosphoketolase pathway that can convert fructose-6-phosphate or xylulose-5-phosphate to acetate-phosphate and erythrose-4-phosphate or glyceraldehyde-3-phosphate, respectively (16). Acetyl-phosphate is further converted to acetyl-CoA by expression of a heterologous phosphotransacetylase. The phosphoketolase pathway subsequently ensures more efficient provision of acetylCoA, a precursor metabolite for sesquiterpene biosynthesis. Several other engineering strategies were also implemented by Amyris, resulting in a heavily engineered strain with a completely altered central carbon metabolism. Similar rewiring has also been performed to obtain high TRYs for free fatty acids (17). These chemicals can be hydrogenated to hydrocarbons, which can then be used as biofuels, as well, such hydrocarbons can also find applications in cosmetics and nutraceuticals. Through combining the expression of a heterologous pathway for provision of acetyl-CoA in

This article is protected by copyright. All rights reserved. 
the cytosol, i.e. ATP:Citrate Lyase, combined with extensive engineering of central carbon metabolism to ensure provision of citrate for this pathway, as well as a sufficient amount of NADPH for fatty acid biosynthesis, it was possible to reach yields of free fatty acids on glucose amounting to $30 \%$ of the maximum theoretical yield (13). Furthermore, with cells been engineered to have a high flux towards fatty acids, it was possible to abolish ethanol fermentation by deletion of pyruvate decarboxylase activity, and thereby convert the cells from being ethanologenic to solely being lipogenic.

Table 1 Scoring of traits for four important cell factories

\begin{tabular}{|c|c|c|c|c|}
\hline Traits & $\begin{array}{c}\text { Escherichia } \\
\text { coli }\end{array}$ & $\begin{array}{c}\text { Corynebacterium } \\
\text { glutamicum }\end{array}$ & $\begin{array}{c}\text { Saccharomyces } \\
\text { cerevisiae }\end{array}$ & $\begin{array}{c}\text { Aspergillus } \\
\text { niger }\end{array}$ \\
\hline Rate & $* * * * *$ & $* * * *$ & $* * *$ & $* *$ \\
\hline Ease of engineering & $* * * * *$ & $* *$ & $* * * * *$ & * \\
\hline $\begin{array}{l}\text { Use of biomass as by- } \\
\text { product }\end{array}$ & $*$ & $*$ & $* * * * *$ & $*$ \\
\hline $\begin{array}{l}\text { Expression of plant } \\
\text { enzymes }^{1}\end{array}$ & $* *$ & $* *$ & $* * * *$ & $* * * * *$ \\
\hline pH tolerance & $*$ & $*$ & $* * * *$ & $* * * * *$ \\
\hline Temperature tolerance & $* * * * *$ & $* * * *$ & $* * *$ & $* * *$ \\
\hline Salt tolerance & $* * *$ & $* * *$ & $* * * *$ & $* * * *$ \\
\hline Substrate spectrum & $* * * *$ & $* * *$ & $* * *$ & $* * * * *$ \\
\hline Robustness $^{2}$ & $* *$ & $* *$ & $* * * * *$ & $* * * * *$ \\
\hline Knowledge base & $* * * * *$ & $* * *$ & $* * * * *$ & $* *$ \\
\hline
\end{tabular}

This article is protected by copyright. All rights reserved. 

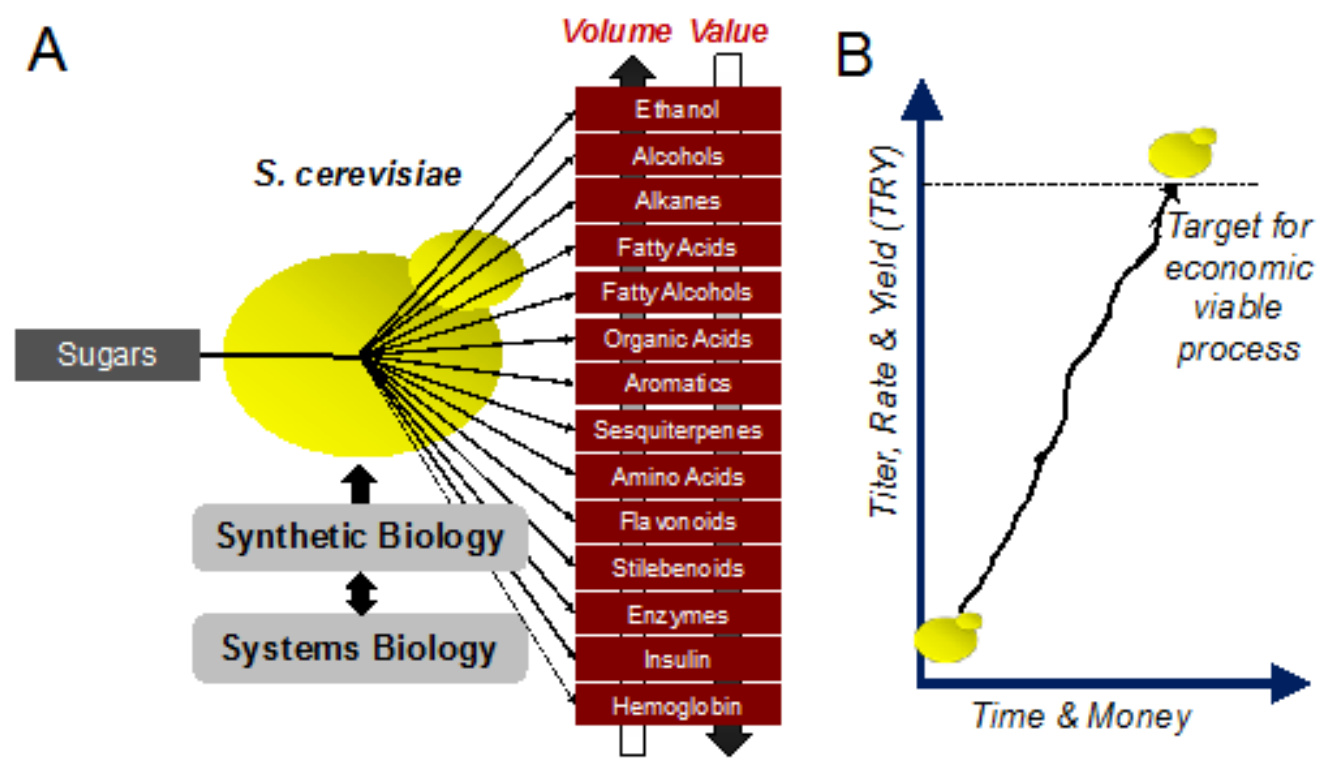

Fig. 2 Yeast as a cell factory platform. A. Using systems biology and synthetic biology yeast metabolism can be engineered to produce a wide range of different chemicals. These range from low-value added, but large volume type products such as ethanol and other biofuels to high-value added, but low volume type products such as pharmaceuticals. B. Following engineering of a strain to produce the molecule of interest, a so-called proof-of-principle strain that often can form the basis for patent protection, it is necessary to improve the TRY in order to establish an industrial process. This takes time and is costly and new technologies are desired to decrease the development time and costs.

Table 2 Non-exhaustive list of various chemicals produced by yeast

$\begin{array}{lll}\text { Chemical class } & \text { Chemical } & \text { Application } \\ \text { Alcohols } & \text { Ethanol } & \text { Drop in biofuel } \\ & \text { Butanol } & \begin{array}{l}\text { Drop in biofuel and precursor for jet } \\ \text { fuels }\end{array}\end{array}$

Reference

Alkanes

Long chain alkanes

Drop in diesel

Short chain alkenes Drop in biofuel

Fatty acids

Oleic acid

Biofuel and lubricants

Octanoic acid

Platform chemical

Fatty alcohols Stearyl alcohol Biofuel and lubricants

This article is protected by copyright. All rights reserved. 


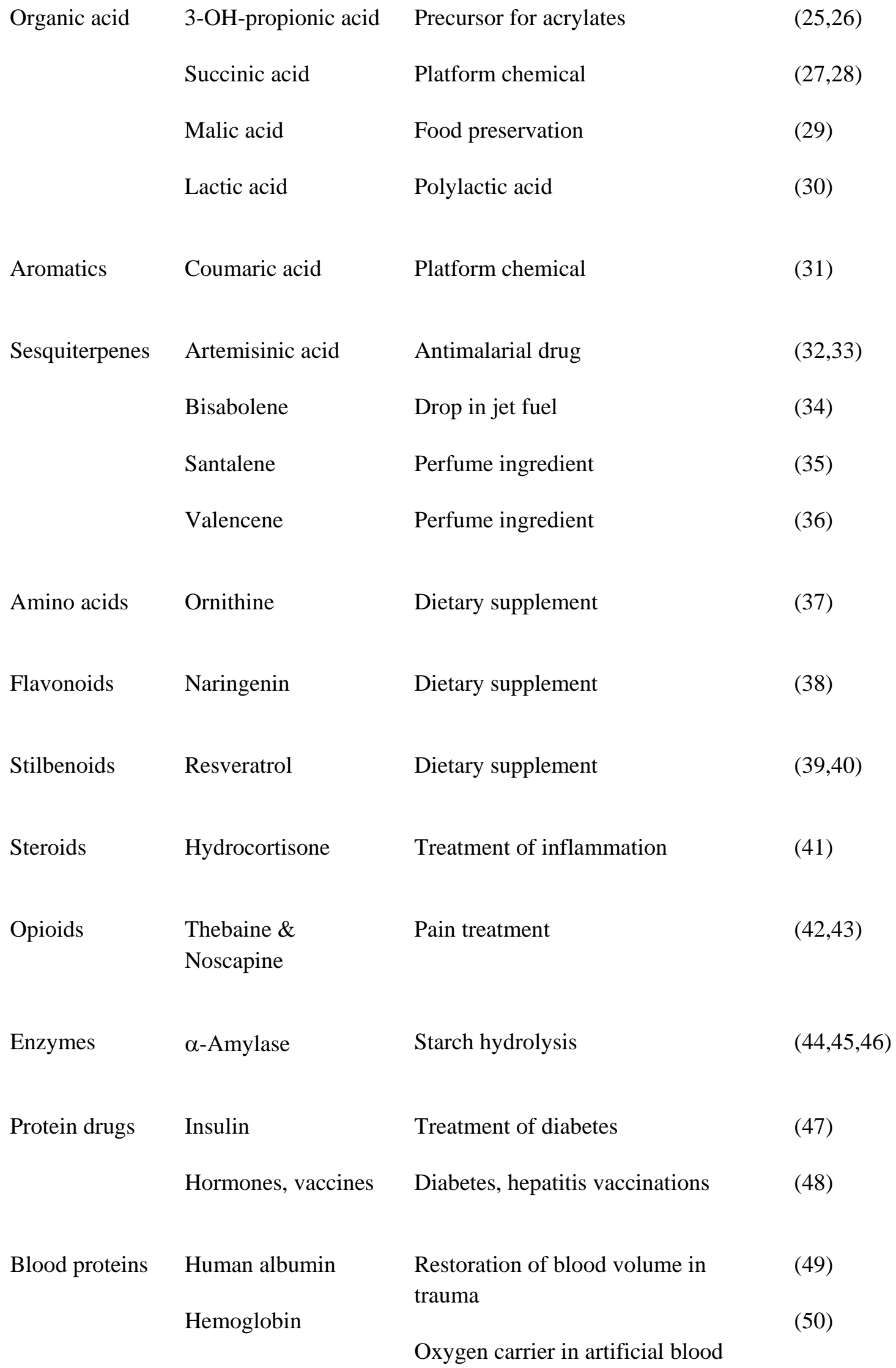

This article is protected by copyright. All rights reserved. 
Yeast can not naturally use pentoses such as xylose and arabinose as carbon source, which is an important trait for a cell factory that should convert lignocellulose into e.g. biofuels. There has therefore been much efforts on engineering yeast such that it can metabolize xylose and arabinose with the objective of establishing so-called second generation bioethanol production. Several different pathways exist for catabolism of xylose (51), but the most efficient pathway is using xylose isomerase that can convert xylose to xylulose in a single step (52). Xylulose can naturally be used as a carbon source by yeast, but the first phosphorylation step has low capacity so it is therefore necessary to also over-express xylulose kinase in order to ensure a high flux of xylose uptake (53). Xylose is transported into the cell via the hexose transporters, and there is therefore competitive inhibition of xylose uptake by glucose. In order to overcome this problem and ensure efficient xylose utilization in the presence of glucose, the hexose transporters have been engineered to having increased affinity towards xylose (54). With these advancements it efficient yeast cell factories for conversion of xylose to ethanol have been established and this has laid the foundation for industrial scale production of second generation bioethanol.

\section{Systems biology}

Systems biology is based on the use of computational and mathematical models for studying biological systems, wherein two different approaches exist (55): 1) top-down systems biology, which generally relies on omics data and often integration of these data sets with comprehensive network models and multivariate statistical analysis; and 2) bottom-up systems biology, based on building mathematical models from biological knowledge, generally describing sub-systems such as regulons or specific pathways. Even though there are many prominent examples wherein bottom-up systems biology was used to get new insight into yeast biology (55), there is a growing trend towards a wider use of top-down systems biology due to it becoming progressively easier to obtain high-quality, quantitative data using omics analysis. In the following I will discuss some key examples of omics analysis and mathematical modeling that demonstrate how systems biology can assist in acquiring new biological knowledge and be used for designing cell factories.

\subsection{Omics analysis}

Omics analysis is defined as the measurement of cellular components and/or their interaction in a high-throughput fashion, i.e. such that all (or at least a very large fraction of all components) are measured at the same time. Omics analysis was pioneered using yeast as a model organism, with the first transcriptome analysis performed in this organism using so-called DNA microarrays (56), followed by many other types of omics analysis, including proteomics, wherein studies with yeast have often been used as a bench mark for new methods (57). Yeast was also used as a model to develop methods for global mapping of transcription factor (TF) binding, i.e. Chromatin Immuno Precipitation (ChIP)-CHIP (58) and ChIP-seq (59), approaches

This article is protected by copyright. All rights reserved. 
that today are still widely used for mapping TF binding in human cells. Recently, we implemented ChIP-exo for more precise mapping of TF binding, and used this to identify the binding of TFs involved in the regulation of lipid metabolism under four different environmental conditions (60). Using the higher resolution ChIP-exo, combined with the characterization of binding at four different conditions, it was possible to identify a large number of new binding targets as well as identify extensive binding overlap events for several different TFs on the same promoters, thus pointing to there being far more complex transcriptional regulation in yeast than previously reported (60). Thus, to identify causal connectivity between TF binding determined by ChIP technologies and transcriptional regulation, it is imperative to generate data for many more conditions, and possibly including data for a larger number of TFs. Nonetheless, with this kind of data at hand it may be possible to use machine learning for developing models that describe the role of TFs in gene expression control. Such models will be valuable for designing promoters and genetic changes required for altering phenotypes, such as genetically rewiring metabolism for high-level production of specific chemicals. This may enable design of new strategies for altering transcriptional regulation of metabolic pathways, which has been shown to be an efficient approach for acquiring new phenotypes such as improved ethanol tolerance (61). In fact improving transcriptional regulation has been found to be an efficient strategy for metabolic engineering, e.g. as illustrated by use of terminators that improves mRNA half-life (62). Detailed models on transcriptional regulation obtained from systems biology can therefore directly impact metabolic engineering and assist in design of cell factories with improved properties.

Yeast is probably the microorganism with the largest repository of transcriptome data. Most older data were generated using DNA microarrays, whereas RNAseq has become the norm today, although good consistency has been proven between the two different approaches (63). One main advantage of RNAseq is that it is quantitative, and with standards it is now possible to measure $>4,000$ mRNAs in yeast cells to absolute levels (64), with it being found that mRNA copy number per cell generally varies across two orders of magnitude, from 1 to 100 per cell. RNAseq is traditionally done using next generation sequencing, but recently it was shown possible to use nanopore sequencing technology, not only to obtain long DNA sequences required for genome assembly, but also for measuring mRNA levels (65).

Proteomics is an area that has advanced significantly in recent years. With state-of-the art proteomics it is now possible to measure $>2,500$ proteins in yeast with a false discovery rate of $<1 \%$ (49). Furthermore, using standards it is possible to measure absolute levels of $>2,000$ proteins in yeast cells (64). Combining such data with quantitative mRNA data at 10 different environmental conditions enabled identification of strong linear relationships between protein and mRNA levels for 202 genes (64). However, the slope of these relationships varied for individual proteins, pointing to large variations in translation rate (protein degradation was also quantified but found not to be an effector). This variation can explain the general poor

This article is protected by copyright. All rights reserved. 
correlation between mRNA and protein levels reported in several studies, but clearly if more data can be obtained, the relationship between transcript and protein abundance for each gene can be established for each gene/protein making it possible to use mRNA levels to predict protein levels in the future.

The metabolome is generally the hardest to capture and measure in a quantitative fashion. This is due to two factors: 1) the very rapid turnover of intracellular metabolites, which requires rapid quenching and extraction of the metabolites (66); and 2) the large chemical diversity of intracellular metabolites, which will require the use of several different analytical methods for their measurements (67). Sauer and coworkers recently presented a very elegant method to overcome the second issue, namely through the use of non-targeted metabolomics using direct injection mass spectrometry (68). They used this approach for performing metabolome analysis of an E. coli single knockout collection with the objective to annotate gene function. Even though this non-targeted metabolomics approach has not yet been applied for analysis in yeast, it could easily be combined with one of the traditionally used quenching and extraction methods developed for this organism (66). Another complication with analyzing metabolomics data is that metabolite concentrations are a function of both protein levels and kinetics of the individual enzymes, and generally there is little knowledge about the in vivo kinetic properties of the enzymes. Using targeted analysis of amino acids in a large gene deletion library it was possible to identify genes having similar function, and further link these to specific regulators such as TORC1 (69). In another recent study from the same group, machine learning was used to correctly predict the yeast metabolome from quantitative proteomics data in several kinase knockout strains (70). This study clearly shows how machine learning can be a powerful tool for integrative analysis of multi-omics data, and with the accumulation of datasets with increasing size and complexity machine learning techniques are likely going to play an increasingly important role in assisting with analysis and extraction of biological information.

\subsection{Mathematical modeling of yeast}

Mathematical models play a central role in engineering where they are used for capturing information in a very concise way, and if the models have good predictive capabilities they can be used for the design of complex systems. Mathematical models are also used in natural sciences to extract information, for examples laws of nature in physics or parameters of certain biological processes, e.g. the Michaelis-Menten kinetics to describe the action of enzymes. With the introduction of molecular biology, it also became the standard to summarize key findings in cartoon models, as exemplified by the lac-operon. However, due to the complexity of metabolism and other cellular function together with the accumulation of knowledge such models become increasingly complex, and do not account sufficiently for quantitative information. There has therefore been an increasing interest to develop mathematical models that quantitatively describe different cellular processes. These models range

This article is protected by copyright. All rights reserved. 
from simple kinetic models that describe the interactions of a few components, to comprehensive single cell models, e.g. a very detailed model developed for E. coli (71). However, with an increasing amount of data, empirical models are also being used more often, e.g. neural network models and other type of models integrated into machine learning algorithms, although here it is often difficult to extract new mechanistic knowledge. Most models fall into one of two categories: 1) kinetic models and 2) flux balance models.

\subsubsection{Kinetic models}

Kinetic models are generally so-called bottom-up models wherein the system is described with a set of variables, e.g. proteins and metabolites, and the interactions of these variables is described by a set of reactions or processes for which rate equations are defined. Often these rate equations take an empirical form, e.g. Michaelis-Menten kinetics for enzyme catalyzed reactions, resulting in a set of parameters that needs to be estimated before the model can be used for simulation purposes. If the model describes molecular mechanisms, the parameters can sometimes be taken from the literature, but most often they have to be estimated through fitting the model to experimental data. The model is therefore first truly evaluated when the model has been compared with an independent set of experimental data. Many different kinetic models have been developed in the area of yeast systems biology, although most have currently been used to study and predict metabolism.

One seminal model was developed by a team led by Matthias Reuss, who developed a detailed kinetic model for yeast glycolysis (72). Besides representing a detailed description of the kinetics of all the individual steps of glycolysis, the study was the first to provide insight into the rapid response of glycolysis to perturbation. Thus, through measurements of glycolytic intermediates with a time resolution of seconds, the authors could demonstrate how a new pseudo-steady state was reached for most metabolites within a few seconds (at most one minute) following a large change in the extracellular glucose concentration (72). This finding strongly supports the concept of flux balance analysis (see below), as clearly metabolism rapidly adapts to a new condition where there is balancing of all fluxes in and out of each metabolite pool.

Another milestone kinetic model is the model of Edda Klipp and co-workers, that described the high-osmolarity glycerol response pathway, involving the mitogenactivated protein (MAP) kinase Hog1 (73). Here the authors correctly described how yeast cells respond to osmotic shock through modeling of several key processes involved in osmo-regulation. This included the MAP-kinase signaling cascade, key reactions of central carbon metabolism (including glycerol production), gene expression, as well as biophysical processes including water flow across a membrane, (73). The model here is particularly impressive as it involves the combination of several different modeling modules, enabling isolation of several different cellular processes, which are activated to ensure osmo-tolerance by the cell. The model was later expanded to cover more metabolic reactions, making it possible to simulate and

This article is protected by copyright. All rights reserved. 
therefore understand how metabolic flux is rerouted towards glycerol as an osmoprotectant (74).

Finally, it is worth mentioning the work of Bas Teusink and co-workers, who in several different studies used kinetic models to get insight into the functioning of glycolysis. In one early study they demonstrated that this important pathway has a socalled Turbo design, due to the initial investment of ATP in sugar phosphorylation, later capturing ATP in downstream glycolysis (75). Unless there is installed regulation of glycolysis this can lead to rapid depletion of ATP if cells are transferred from conditions with low sugar concentrations to high sugar concentrations. Yeast has evolved to have a "brake" on the initial sugar phosphorylation by hexokinase to prevent drainage of ATP. This "brake" is caused by trehalose-6-phosphate (T6P), formed from glucose-6-phosphate, and serving as an inhibitor of hexokinase. Using this simple kinetic model, Teusink and co-workers could therefore capture the crucial role of this regulatory design (64). This important role of T6P can also explain why a yeast strain that lacks trehalose-6-phosphate synthase (Tps1) cannot grow when glucose is in excess (76). More recently Teusink and co-workers performed a far more thorough analysis of the role of Tps1 in controlling glycolysis and growth of yeast at high glucose concentrations, and found that yeast may be able to survive without this enzyme given the right initial concentration of glycolytic intermediates (77). Due to cell heterogeneity, this would allow a sub-population of cells in a culture lacking Tps1 activity to actually survive and eventually take over the population. Their extensive analysis combining detailed mathematical modeling with multi-omics analysis is subsequently an excellent example of how systems biology can provide new insight into the physiology of yeast (78).

\subsubsection{Flux balance models}

Flux balance analysis (FBA) is a modeling concept that has been extensively used for about 30 years (51), and relies on balancing fluxes around metabolites in the model. In other words, the sum of fluxes into a metabolite pool equals the sum of fluxes leaving this metabolite pool. The resulting balance equations provide a set of constraints on the fluxes, and this concept is therefore also often referred to as constraint-based analysis (79). Using this concept it is possible to calculate all the metabolic fluxes using a few measured fluxes as additional constraints, and often also using an objective function. Originally FBA was used for small scale models that captured primarily central carbon metabolism but with the introduction of genome-sequences it became possible to reconstruct cellular metabolism at the genome-scale, resulting in so-called genome-scale metabolic models (GEMs). FBA has been used extensively for analysis of yeast metabolism and in 2003 the first GEM was reconstructed for yeast (80). This model has been updated in several rounds by different research groups and in 2008 this inspired several groups to collaborate and establish a so-called consensus GEM for yeast, often referred to as Yeast (81). This consensus GEM has subsequently been updated in several rounds (82), and we are currently working on

This article is protected by copyright. All rights reserved. 
Yeast8, which is made freely available at https://github.com/SysBioChalmers/yeastGEM ahead of publication, in order to be a general resource for the yeast community. Through having the GEM as a freely available model it will also be possible to continuously update the model in a community effort, thereby making the model an increasingly valuable resource for capturing information about yeast metabolism.

GEMs together with FBA has been used extensively for studies of yeast metabolism as well as for the design of cell factories, e.g. to develop a strain that has succinic acid production coupled with growth (27). However, the predictive strength of traditional FBA is limited, as the concept does not account for kinetics of individual enzymes, and as a result the capacity of each pathway to carry a certain flux is not constrained. This can be overcome by adding constraints on the flux through each of the reactions, defined by both enzyme $k_{\text {cat }}$ and enzyme concentration. An additional constraint on the total enzyme pool further improves the prediction. Applying these constraints on a relatively simple model, where only enzymes of the central carbon metabolism were considered, it was possible to describe the so-called Crabtree effect, i.e. overflow towards ethanol when yeast is growing fast at un-restricted glucose concentrations (83). The modeling gave new insight into this well studied phenomenon, and showed clearly that the Crabtree effect is resulting from a relatively low catalytic efficiency of the tricarboxylic acid (TCA) cycle and the respiratory system, and in particular pointing to a key role of $\mathrm{F}_{1} \mathrm{~F}_{\mathrm{O}}$-ATP Synthase, a very large enzyme with a relatively low $k_{\text {cat }}(83)$. This modeling clearly showed that the concept of proteome constraints, together with information on catalytic efficiency of individual enzymes in the model represents a very powerful approach to simulate metabolism. We therefore expanded further this concept to cover all enzymes in the GEM Yeast7.6, referred to as an enzyme constrained model (84), i.e. ecYeast7.6. Besides also being able to describe the Crabtree effect, this expanded modeling approach, referred to as GECKO, also enabled better prediction of growth on different carbon sources as well as the impact of different genetic modifications (84). Furthermore, as GECKO is compatible with proteomics data, it is suitable for integrative analysis of similar quantitative omics data.

The next step in modeling will naturally be to expand the GECKO modeling concept further to account for protein synthesis and translocation to different compartments. This is in analogy with the so-called ME (metabolism and protein expression) model generated for $E$. coli (85), now also accounting for differences in $k_{\text {cat }}$ values as well as protein constraints in different compartments, such as mitochondria, endoplasmic reticulum and the plasma membrane. We have already generated such a model and it has been shown to have excellent predictive strength (non-published results), referring to this type of model as a proteome constrained model, i.e. pcYeast7.6.

This article is protected by copyright. All rights reserved. 


\section{Perspectives}

As it has become easier to perform studies on human cell lines the need for yeast as an eukaryal model organism has decreased, but still it has much to offer as a model organism. Due to its relatively small genome, relative simplicity in terms of regulation, availability of excellent research infrastructures such as the Saccharomyces Genome Database, and availability of both gene deletion and overexpression libraries, yeast is still widely used as a model organism. Furthermore, with the development of many new techniques for generating high-throughput data it has become possible to generate very large experimental data-sets of high-quality for yeast, and these will further advance our understanding of the functioning of an eukaryal cell. As discussed, GEMs are beginning to establish themselves as a strong platform for performing integrative analysis of such quantitative data and transform them into knowledge. Moreover, the GEM modeling concept allows for further expansion as discussed, e.g. to consider protein synthesis and translocation, enabling these models to capture increasingly greater number of features connected to yeast physiology. However, for some processes, e.g. transcriptional regulation, where there may be an element of stochasticity as well as epistasis, it may be very difficult, to develop traditional mechanistic models. In these cases, it may be necessary to rely on machine learning techniques. However, such models may well be combined with GEMs, that currently remain the best modeling platform for describing all key cellular processes in a single mathematical model. Such a model will be very valuable for gaining novel physiological insight as well as for design of efficient cell factories. I am therefore confident that also in the future there will be excellent synergy between the use of yeast as a model organism for studying eukaryal biology and the use of yeast as a cell factory.

\section{Acknowledgements}

I would like to thank Rosemary Yu, Kate Campbell and Hongzhong Lu for valuable comments to this paper. I would also like to acknowledge generous funding over the last 10 years to my research group from the Novo Nordisk Foundation and the Knut and Alice Wallenberg Foundation. I also acknowledge funding to my group from Vetenskapsrådet, the Swedish Foundation for Strategic Research, FORMAS, Energimyndigheten and Horizon2020.

\section{Conflict of interests}

Jens Nielsen is shareholder in Biopetrolia AB.

This article is protected by copyright. All rights reserved. 


\section{References}

1. McGovern, P., Jalabadze, M., Batiuk, S., Callahan, M.P., Smith, K.E., Hall, G.R., Kvadadze, E., Maghradze, D., Rusishvili, N., Bouby, L., Failla, O., Cola, G., Mariani, L., Boaretto, E., Bacilieri, R., This, P., Wales, N., Lordkipanidze, D., Early Neolithic wine of Georgia in the South Caucasus. Proc. Nat. Acad. Sci. USA 2017, 114, E10309-E10318

2. Money, N.P., The rise of yeast. How the sugar fungus shaped civilization. 2018. Oxford University Press, New York, USA

3. Glamann, K., Glamann, K., The story of Emil Chr. Hansen. 2009.The Carlsberg Foundation, Copenhagen, Denmark

4. Jackson, P., De Chiara, M., Friedrich, A., Yue, J.X., Pflieger, D., Bergström, A., Sigwalt, A., Barre, B., Freel, K., Llored, A., Cruaud, C., Labadie, K., Aury, J.-M., Istace, B., Lebrigand, K., Barbry, P., Engelen, S., Lemainque, A., Wincker, P., Liti, G., Genome evolution across 1,011 Saccharomyces cerevisiae isolates. Nature 2018, 556, 339-344

5. Hohmann, S. Nobel yeast research. FEMS Yeast Res. 2016, 16, fow094

6. Nielsen, J., Production of biopharmaceutical proteins by yeast. Advances through metabolic engineering. Bioengineered 2013, 4, 207-211

7. Botstein, D., Fink, G.R. Yeast: an experimental organism for modern biology. Science 1988, 240, 1439-1443

8. Kachroo, A.H., Laurent, J.M. Yellman, C.M., Meyer, A.G., Wilke, C.O., Marcotte, E.M., Systematic humanization of yeast genes reveals conserved functions and genetic modularity. Science 2015, 348, 921-925

9. Celenza, J.L., Carlson, M. A yeast gene that is essential for release from glucose repression encodes a protein kinase. Science, 1986, 233, 1175-1180

10. Usaite, R., Jewett, M.C., Oliveira, A.P., Yates III, J.R., Olsson, L., Nielsen, J., Reconstruction of the yeast Snf1 kinase regulatory network reveals its role as a global energy regulator. Mol. Systems Biol. 2009, 5, 319

11. Zhang, J., Vaga, S., Chumnanpuen, P., Kumar, R., Vemuri, G.N., Aebershold, R., Nielsen, J., Mapping the interaction of Snf1 with TORC1 in Saccharomyces cerevisiae. Mol. Systems Biol. 2011, 7, 545

12. Nakamura, C.E., Whited, G.M. Metabolic engineering for the microbial production of 1,3 propanediol. Curr. Opin. Biotechnol. 2003, 14, 454-459

13. Yim, H., Haselbeck, R., Niu, W., Pujol-Baxley, C., Burgard, A., Boldt, J., Khandurina, J., Trawick, J.D., Osterhout, R.E., Stephen, R., Estadilla, J., Teisan, S., Schreyer, H.B., Andrae, S., Yang, T.H., Lee, S.Y., Burk, M.J., Van Dien, S., Metabolic engineering of Escherichia coli for direct production of 1,4 butanediol. Nature Chem. Biol. 2011, 7, 445-452

14. Nielsen, J. Yeast cell factories on the horizon. Science 2015, 349, 1050-1051

15. Nielsen, J., Keasling, J.D. Engineering cellular metabolism. Cell 2016, 164, 11851197

16. Meadows, A.L., Hawkins, K.M., Tsegaye, Y., Antipov, E., Kim, Y., Raetz, L., Dahl, R.H., Tai A., Mahatdejkul-Meadows, T., Xu, L., Zhao. L., Dasika, M.S., Murarka, A., Lenihan, J., Eng, D., Leng, J.S., Liu, C.-L., Wenger, J.W., Jiang, H., Chao, L., Westfall, P., Lai, J., Ganesan, S., Jackson, P., Mans, R., Platt, D., Reeves, C.D., Saija, P.R., Wichmann, G., Holmes, V.F., Benjamin, K., Hill, P.W., Gardner, T.S., Tsong,

This article is protected by copyright. All rights reserved. 
A.E., Rewriting yeast central carbon metabolism for industrial isoprenoid production. Nature 2016, 537, 694-697

17. Yu, T., Zhou, Y.J., Huang, M., Liu, Q., Pereira, R., David, F., Nielsen, J., Reprogramming yeast metabolism from alcoholic fermentation to lipogenesis. Cell 2018, 174, 1549-1558

18. Caspeta, L., Chen, Y., Ghiaci, P., Feizi, A., Buskov, S., Hallström, B.M., Petranovic, D., Nielsen, J., Altered sterol composition renders yeast thermotolerant. Science 2014, 324, 1029-1033

19. Steen, E.J., Chan, R., Prasad, N., Myers, S., Petzold, C.J., Redding, A., Ouellet, M., Keasling, J.D., Metabolic engineering of Saccharomyces cerevisiae for the production of $n$-butanol. Microb. Cell Fact. 2008, 7, 36

20. Krivoruchko, A., Serrano-Amatriain, C., Chen, Y., Siewers, V., Nielsen, J. Improving biobutanol production in engineered Saccharomyces cerevisiae by manipulation of acetyl-CoA metabolism. J. Ind. Microbiol. Biotechnol. 2013, 40, 1051-1056

21. Zhou, Y.J., Buijs, N.A., Zhu, Z., Gomez, D.O., Boonsombuti, A., Siewers, V., Nielsen, J., Harnessing yeast peroxisomes for biosynthesis of fatty-acid-derived biofuels and chemicals with relieved side-pathway competition. J. Amer. Chem. Soc. 2016, 138, 15368-15377

22. Zhu, Z., Zhou, Y.J., Kang, M.-K., Krivoruchko, A., Buijs, N.A., Nielsen, J., Enabling the synthesis of medium chain alkanes and 1-alkanes in yeast. Met. Eng. 2017, 44, 8188

23. Zhou, Y.J., Buijs, N.A., Zhu, Z., Qin, J., Siewers, V., Nielsen, J., Production of fatty acid-derived oleochemicals and biofuels by synthetic yeast cell factories. Nature Com. 2016, 7, 11709

24. Zhu, Z., Zhou, Y.J., Krivoruchko, A., Grininger, M., Zhao, Z.K., Nielsen, J., Expanding the product portfolio of fungal type I fatty acid synthases. Nature Chem. Biol. 2017, 13, 360-362

25. Borodina, I., Kildegaard, K.R., Jensen, N.B., Blicher, T.H., et al., Establishing a synthetic pathway for high-level production of 3-hydroxypropionic acid in Saccharomyces cerevisiae via $\beta$-alanine. Met. Eng. 2015, 27, 57-64

26. Chen, Y., Bao, J., Kim, I.-K., Siewers, V., Nielsen, J. Coupled incremental precursor and co-factor supply improves 3-hydroxypropionic acid production in Saccharomyces cerevisiae. 2014, 22, 104-109

27. Otero, J.M., Cimini, D., Patil, K.R., Poulsen, S.G., Olsson, L., Nielsen, J., Industrial systems biology of Saccharomyces cerevisiae enables novel succinic acid cell factory. PLOS One 2013, 8, e54144

28. Ito, Y., Hirasawa, T., Shimizu, H. Metabolic engineering of Saccharomyces cerevisiae to improve succinic acid production based on metabolic profiling. Biosci. Biotechnol. Biochem. 2014, 78, 151-159

29. Zelle, R.M., de Hulster, E., van Winden, W.A., de Waard, P., Dijkema, C., Winkler, A.A., Geertman, J.-M.A., van Dijken, J.P., Pronk, J.T., van Maris, A.J.A., Malic acid production by Saccharomyces cerevisiae: Engineering of pyruvate carboxylation, oxaloacetate reduction and malate export. Appl. Environ. Microbiol. 2008, 74, 27662777

30. Porro, D., Brambilla, L., Ranzi, B.M., Martegani, E., Alberghina, L. Development of metabolically engineered Saccharomyces cerevisiae cells for the production of lactic acid. Biotechnol. Prog. 1995, 11, 294-298

This article is protected by copyright. All rights reserved. 
31. Rodriguez, A., Kildegaard, K., Li, M., Borodina, I., Nielsen, J. Establishment of a yeast platform strain for production of $p$-coumaric acid through metabolic engineering of aromatic amino acid biosynthesis. Met. Eng. 2015, 31, 181-188

32. Ro., D.-K., Paradise, E.M., Ouellet, M., Fisher, K.J., Newman, K.L., Ndungu, J.M., Ho, K.A., Eachus, R.A., Ham, T.S., Kirby, J., Chang, M.C.Y., Withers, S.T., Shiba, Y., Sarpong, R., Keasling, J.D., Production of the antimalarial drug precursor artemisinic acid in engineered yeast. Nature 2006, 440, 940-943

33. Westfall, P.J., Pitera, D.J., Lenihan, J.R., Eng, D., Woolard, F.X., Regentin, R., Horning, T., Tsuruta, H., Melis, D.J., Owens, A., Fickes, S., Diola, D., Benjamin, K.R., Keasling, J.D., Leavell, M.D., McPhee, D.J., Renninger, N.S., Newman, J.D., Paddon, C.J., Production of amorphadiene in yeast, and its conversion to dihydroartemisinic acid, precursor to the antimalarial agent artemisinin. Proc. Nat. Acad. Sci. USA 2012, 109, E111-E118

34. Peralta-Yahya, P.P., Ouellet, M., Chan, R., Mukhopadhyay, A., Keasling, J.D., Lee T.S., Identification and microbial production of a terpene-based advanced biofuel. Nature Com. 2011, 2, 483

35. Scalcinati, G., Knuf, C., Partow, S., Chen, Y., Maury, J., Schalk, M., Daviet, L., Nielsen, J., Siewers, V., Dynamic control of gene expression in Saccharomyces cerevisiae engineered for the production of plant sesquiterpene $\alpha$-santalene in fedbatch mode. Met. Eng. 2012, 14, 91-103

36. Asadollahi, M.A., Maury, J., Møller, K., Nielsen, K.F., Schalk, M., Clark, A., Nielsen, J., Production of plant sesquiterpenes in Saccharomyces cerevisiae: Effect of ERG9 repression on sesquiterpene biosynthesis. Biotechnol. Bioeng. 2008, 99, 666677

37. Qin, J., Zhou, Y.J., Krivoruchko, A., Huang, M., Liu, L., Khoomrung, S., Siewers, V., Jiang, B., Nielsen, J., Modular pathway rewiring of Saccharomyces cerevisiae enables high-level production of L-ornithine. Nature Com. 2015, 6, 8224

38. Koopman, D., Beekwilder, J., Crimi, B., van Houwelingen, A., Hall, R.D., Bosch, D., van Maris, A.J.A., Pronk, J.T., Daran, J.-M., De novo production of the flavonoid naringenin in engineered Saccharomyces cerevisiae. Microb. Cell Fact. 2012, 11, 155

39. Li, M., Kildegaard, K.R., Chen, Y., Rodriguez, A., et al., De novo production of resveratrol from glucose or ethanol by engineered Saccharomyces cerevisiae. Met. Eng. 2015, 32, 1-11

40. Li, M., Schneider, K., Kristensen, M., Borodina, I., Nielsen, J. Engineering yeast for high-level production of stilbenoid antioxidants. Sci. Rep. 2016, 6, 36827

41. Szczebara, F.M., Chandelier, C., Villeret, C., Masurel, A., Bouret, S., Duport, C., Blanchard, S., Groisillier, A., Testet, E., Costaglioli, P., Cauet, G., Degryse, E., Balbuena, D., Winter, J., Achstetter, T., Spagnoli, R., Pompon, D., Dumas, B., Total biosynthesis of hydrocortisone from a simple carbon source in yeast. Nature Biotechnol. 2003, 21, 143-149

42. Galanie, S., Thodey, K., Trenschard, I.J., Interrante, M.F., Smolke, C. Complete biosynthesis of opioids in yeast. Science 2015, 349, 1095-1100

43. Li, Y., Li, S., Thodey, K., Trenschard, I., Cravens, A., Smolke, C.D., Complete biosynthesis of noscapine and halogenated alkaloids in yeast. Proc. Nat. Acad. Sci. USA 2018, 115, E3922-E3931

44. Huang, M., Bai, Y., Sjostrom, S.L., Hallström, B.M., Liu, Z., Petranovic, D., Uhlen, M., Joensson, H.N., Andersson-Svahn, H., Nielsen, J., Microfluidics screening and

This article is protected by copyright. All rights reserved. 
whole-genome sequencing identifies mutations associated with improved protein secretion by yeast. Proc. Nat. Acad. Sci. USA 2015, 112, E4689-E4696

45. Huang, M., Bao, J., Hallström, B.M., Petranovic, D., Nielsen, J. Efficient protein production by yeast requires global tuning of metabolism. Nature Com. 2017, 8, 1131

46. Huang, M., Wang, G., Qin, J., Petranovic, D., Nielsen, J. Engineering the protein secretory pathway of Saccharomyces cerevisiae enables improved protein production. Proc. Nat. Acad. Sci. USA 2018, 115, E11025-E11032

47. Liu, Z., Tyo, K.E.J., Martinez, J.L., Petranovic, D., Nielsen, J. Different expression systems for production of recombinant proteins in Saccharomyces cerevisiae. Biotechnol. Bioeng. 2012, 109, 1259-1268

48. Huang, M., Bao, J., Nielsen, J. Biopharmceutical protein production by Saccharomyces cerevisiae: current state and future prospects. Pharma. Bioproc. 2014, 2, 167-182

49. Sleep, D., Belfield, G.P., Goodey, A.R. The secretion of human serum albumin from the yeast Saccharomyces cerevisiae using five different leader sequences. Nature Biotechnol. 1990, 8, 42-46

50. Liu, L., Martinez, J.L., Liu, Z., Petranovic, D., Nielsen, J. Balanced globin protein expression and heme biosynthesis improve production of human hemoglobin in Saccharomyces cerevisiae. Met. Eng. 2014, 21, 9-16

51. Li, X., Chen, Y., Nielsen, L. Harnessing xylose pathways for biofuels production. Cur. Op. Biotechnol. 2019, 57, 56-65

52. Kuyper, M., Harhangi, H.R., Stave, A.K., Winkler, A.A., Jetten, M.S.M., de Laat, W.T., den Ridder, J.J., Op den Camp, H.J., van Dijken, J.P., Pronk, J.T., High-level functional expression of a fungal xylose isomerase: the key to efficient ethanolic fermentation of xylose by Saccharomyces cerevisiae? FEMS Yeast Res. 2003, 4, 6978

53. Kuyper, M., Hartog, M.M.P., Toirkens, M.J., Almering, M.J.H., Winkler. A.A., van Dijken, J.P., Pronk, J.T., Metabolic engineering of a xylose-isomerase expressing Saccharomyces cerevisiae strain for rapid anaerobic xylose fermentation. FEMS Yeast Res., 2005, 5, 399-409

54. Young, E.M., Tong, A., Bui, H., Spofford, C., Alper, H.S. Rewiring yeast sugar transporter preference through modifying a conserved protein motif. Proc. Nat. Acad. Sci. USA, 2014, 111, 131-136

55. Nielsen, J. Systems biology of metabolism. Ann. Rev. Biochem. 2017, 86, 245-276

56. DeRisi, J.L., Iyer, V.R., Brown, P.O. Exploring the metabolic and genetic control of gene expression on a genome scale. Science 1997, 278, 680-686

57. Picotti, P., Clement-Ziza, M., Lam, H., Campbell, D.S., Schmidt, A., Deutsch, E.W., Röst, H., Sun, Z., Rinner, O., Reiter, L., Shen, Q., Michaelson J.J., Frei, A., Alberti, S., Kusebauch, U., Wollscheid, B., Moritz, R., Beyer, A., Aebershold, R., A complete mass spectrometric map for the analysis of the yeast proteome and its application to quantitative trait analysis. Nature 2013, 494, 266-270

58. Harbinson, C.T., Gordon, D.B., Lee, T.I., Rinaldi, N.J., Macisaac, K.D., Danford, T.W., Hannett, N.M., Tagne, J.B., Reynolds, D.B., Yoo, J., Jennings, E.G., Zeitlinger, J., Pokholok, D.K.; Kellis, M., Rolfe, P.A., Takusagawa, K.T., Lander, E.S., Gifford, D.K., Fraenkel, E. Young, R.A., Transcriptional regulatory code of a eukaryotic genome. Nature 2004, 431, 99-104

59. Johnson, D.S., Mortazavi, A., Myers, R.M., Wold, B. Genome-wide mapping of in vivo protein-DNA interactions. Science 2007, 316, 1497-1502

This article is protected by copyright. All rights reserved. 
60. Bergenholm, D., Liu, G., Holland, P., Nielsen, J. Reconstruction of a global transcriptional regulatory network for control of lipid metabolism in yeast using chromatin immunoprecipitation with lambda exonuclease digestion. mSystems 2018, 3, e00215-17

61. Alper, H., Moxley, J., Nevoigt, E., Fink, G.R., Stephanopoulos, G. Engineering yeast transcription machinery for improved ethanol tolerance and production. Science, 2006, 314, 1566-1568

62. Curran, K.A., Karim, A.S., Gupta, A., Alper, H.S. Use of high capacity terminators in Saccharomyces cerevisiae to increase mRNA half-life and improve gene expression control for metabolic engineering applications. Met. Eng., 2013, 19, 88-97

63. Nookaew, I., Papini, M., Pornputtapong, N., Scalcinati, G., Fagerberg, L., Uhlen, M., Nielsen, J., A comprehensive comparison of RNA-Seq-based transcriptome analysis from reads to differential gene expression and cross-comparison with microarrays: a case study in Saccharomyces cerevisiae. Nuc. Acid Res. 2012, 40, 10084-10097

64. Lahtvee, P.-J., Sanchez, B.J., Smialowska, A., Kasvandik, S. et al., Absolute quantification of protein and mRNA abundances demonstraste variability in genespecific translation efficiency in yeast. Cell Syst. 2017, 4, 495-504

65. Jenjaroenpun, P., Wongsurawat, T., Pereira, R., Patumcharoenpol, P., Ussery, D.W., Nielsen, J., Nookaew, I., Complete genomic and transcriptional landscape analysis using third-generation sequencing: a case study of Saccharomyces cerevisiae CEN.PK113-7D. Nucl. Acid Res. 2018, 46, e38

66. Villas-Boas, S.G., Højer-Pedersen, J., Åkesson, M., Smedsgaard, J., Nielsen, J. Global metabolite analysis of yeast: evaluation of sample preparation methods. Yeast 2005, 22, 1155-1169

67. Villas-Boas, S.G., Mas, S., Åkesson, M., Smedsgaard, J., Nielsen, J. Mass spectrometry in metabolome analysis. Mass Spectrom. Rev. 2005, 24, 613-646

68. Fuhrer, T., Zampieri, M., Sevin, D.C., Sauer, U., Zamboni, N. Genomewide landscape of gene-metabolome associations in Escherichia coli. Mol. Systems Biol. 2017, 13, 907

69. Mülleder, M., Calvani, E., Alam, M.T., Wang, R.K., Eckerstorfter, F., Zeleznika, A., Ralser, M., Functional metabolomics describes the yeast biosynthetic regulome. Cell 2016, 167, 553-565

70. Zelezniak, A., Vowinckel, J., Capuano, F., Messner, C.B., et al., Machine learning predicts the yeast metabolome from the quantitative proteome of kinase knockouts. Cell Systems 2018, 7, 269-283

71. Karr, J.R., Sanghvi, J.C., MacKlin, D.N., Gutschow, M.V., Jacobs, J.M., Bolival, B., Assad-Garcia, N., Glass, J.I., Covert, M.W., A whole-cell computational model predicts phenotype from genotype. Cell 2012, 150, 389-401

72. Rizzi, M., Baltes, M., Theobald, U., Reuss, M. In vivo analysis of metabolic dynamics in Saccharomyces cerevisiae: II. Mathematical model. Biotechnol. Bioeng. 1997, 55, 592-608

73. Klipp, E., Nordlander, B., Krüger, R., Gennemark, P., Hohmann, S. Integrative model of the response of yeast to osmotic shock. Nature Biotechnol. 2005, 23, 975-982

74. Petelenz-Kurdziel, E., Kuehn, C., Nordlander, B., Klein, D., Hong, K.-K., Jacobson, Dahl, P., Schaber, J., Nielsen, J., Hohmann, S., Klipp, E., Quantitative analysis of glycerol accumulation, glycolysis and growth under hyper osmotic stress. PLOS Comp. Biol. 2012, 9, e1003084

This article is protected by copyright. All rights reserved. 
75. Teusink, B., Walsch, M.C., van Dam, K., Westerhoff, H.V. The danger of metabolic pathways with turbo design. Trends Biochem. Sci. 1998, 23, 162-169

76. van de Poll, K., Kerkenaar, A., Schambart, D.H.J. Isolation of a regulatory mutant of fructose-1,6 diphosphatase in Saccharomyces cerevisiae. J. Bacteriol. 1974, 117, 965970

77. van Heerden, J.H., Wortel, M.T., Bruggeman, F.J., Heijnen, J.J., Bollen, Y.J., Planque, R., Hulshof, J., O’Toole, T.G., Wahl, S.A., Teusink, B., Lost in translation: start-up of glycolysis yields subpopulations of non-growing cells. Science 2014, 343, 1245114

78. Fraenkel, D., Nielsen, J. Trehalose-6-phosphate synthase and stabilization of yeast glycolysis. FEMS Yeast Res. 2016, 16, fov100

79. O’Brien, E.J., Monk, J.M., Palsson, B. Using genome-scale models to predict biological capabilities. Cell 2015, 161, P971-987

80. Förster, J., Famili, I., Fu, P., Palsson, B., Nielsen, J. Genome-scale metabolic reconstruction of the Saccharomyces cerevisiae metabolic network. Genome Res. 2003, 13, 244-253

81. Herrgård, M.J., Swainston, N., Dobson, P., Dunn, W.B., Arga, K.Y., Arvas, M., Blüthgen, N., Borger, S., Costenboble, R., Heinemann, M., Hucka, M., Le Novère, N., Li, P., Liebermeister, W., Mo, M.L., Oliveira, A.P., Petranovic, D., Pettifer, S., Simeonidis, E., Smallbone, K., Spasic, I., Weichart, D., Brent, R., Broomhead, D.S., Westerhoff, H.V., Kirdar, B., Penttilä, M., Klipp, E., Palsson, B.Ø., Sauer, U., Oliver, S.G., Mendes, P., Nielsen, J., Kell, D.B., A consensus yeast metabolic network reconstruction obtained from a community approach to systems biology. Nature Biotechnol. 2008, 26, 1155-1160

82. Sanchez, B.J., Nielsen, J. Genome-scale models of yeast: towards standardized evaluation and consistent omic integration. Integr. Biol. 2015, 7, 846-858

83. Nilsson, A., Nielsen, J. Metabolic trade-offs in yeast are caused by F1FO-ATP synthase. Sci. Rep. 2016, 6, 22264

84. Sanchez, B.J., Zhang, C., Nilsson, A., Lahtvee, P.-J., Kerkhoven, E.J., Nielsen, J., Improving the phenotypic predictions of a yeast genome-scale metabolic model by incorporating enzymatic constraints. Mol. Sys. Biol. 2017, 13, 935

85. Thiele, I., Ronan, M.T.F., Que, R., Bordbar, A., Diep, D., Palsson, B.O., Multiscale modeling of metabolism and macromolecular synthesis in E. coli and its applications to the evolution of codon usage. PLOS ONE 2012, 7, e45635

This article is protected by copyright. All rights reserved. 